\title{
Working with CRSP/COMPUSTAT in R: Reproducible Empirical Asset Pricing
}

by Majeed Simaan

\begin{abstract}
It is common to come across SAS or Stata manuals while working on academic empirical finance research. Nonetheless, given the popularity of open-source programming languages such as R, there are fewer resources in R covering popular databases such as CRSP and COMPUSTAT. The aim of this article is to bridge the gap and illustrate how to leverage $\mathrm{R}$ in working with both datasets. As an application, we illustrate how to form size-value portfolios with respect to Fama and French (1993) and study the sensitivity of the results with respect to different inputs. Ultimately, the purpose of the article is to advocate reproducible finance research and contribute to the recent idea of "Open Source Cross-Sectional Asset Pricing", proposed by Chen and Zimmermann (2020).
\end{abstract}

\section{Overview}

Typically the CRSP and COMPUSTAT databases are viewed as the cornerstones of academic empirical finance research. The former corresponds to security-related information for publicly listed companies, such as closing prices and returns. The latter covers financial statements disclosed by public firms, such as income statement, balance sheet, and cash-flow related items. We begin our discussion by demonstrating how to clean, manipulate, and merge both datasets. After doing so, we conduct the main analysis from the perspective of empirical asset pricing research based on Fama and French (1993).

The undertaken analysis constitutes a typical portfolio formation procedure to investigate how investors are compensated for taking certain types of risk/style. By grouping firms (stocks) with respect to pre-specified attributes, the researcher can study the implications of these characteristics (risks) in association with future returns. Such analysis is known as the cross-section of expected return (see, e.g., Harvey et al. (2016)) since the relationship is investigated on the firm/portfolio level. Consistent with Harvey et al. (2016), we find that the results of the cross-section of expected returns are sensitive to the research design. In particular, the exclusion of small stocks in the sample has a significant economic impact. Small stocks tend to trade less frequently and to be less liquid. Hence, in order to better understand the cross-section of expected returns, one needs to take into consideration the underlying limits of arbitrage facing investors (Li et al., 2014).

We hope this article would further contribute to reproducible finance research and to our understandings of the cross-sectional of expected returns. The article proceeds as follows. In Section 2.2, we discuss how to load each dataset along with the pre-analysis needed in order to merge the data altogether. Section 2.3 is devoted to the replication of Fama and French (1993)'s size and value premiums. The analysis is conducted using raw and risk-adjusted returns. Section 2.4 then proceeds to investigate the sensitivity of the cross-section of returns with respect to the research design. Finally, Section 2.6 concludes.

\section{Data}

The discussion assumes that the user has already downloaded the CRSP and the COMPUSTAT datasets in two separate files, both in csv formats. ${ }^{1}$ The article will rely on different libraries to perform the analysis. The core packages of interest are data.table (Dowle and Srinivasan, 2019) and lubridate (Grolemund and Wickham, 2011). We also refer to ggplot2 (Wickham, 2016) to produce figures and parallel (R Core Team, 2020) to perform parallel processing. In a few cases, we refer to plyr (Wickham, 2011) and dplyr (Wickham et al., 2020) for additional data manipulation. Nonetheless, the main analysis is conducted in the data.table environment.

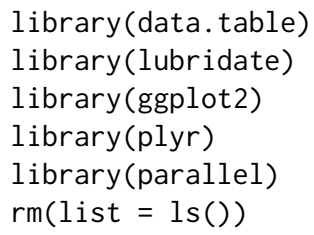

\footnotetext{
${ }^{1}$ Note that users can work with the database directly using the WRDS API.
} 


\section{CRSP}

While there are a lot of pros to working data.table, one good functionality is the option that allows the user to easily specify a subset of variables while reading the whole data. Mostly, after downloading the full dataset, we focus on a subset of variables of interest. We refer to its main function fread, rather than the base command read.csv. The fread is similar to the base command; however, it provides faster and more convenient data manipulation. It is highly relevant when it comes to large data. Additionally, it allows users to easily utilize multi-threads using the nThread argument.

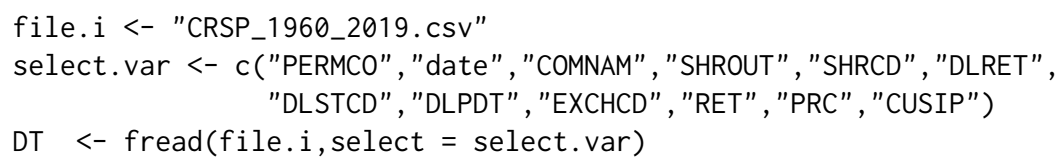

The above commands load the monthly CRSP dataset with pre-specified variables. Those are the permanent identifier of the security (PERMCO), date, shares outstanding in thousands (SHROUT), share code (SHRCD), exchange code (EXCHCD), security return RET, price PRC, and the CUSIP identifier. Note that the CUSIP is the key link between the CRSP and COMPUSTAT data. Additionally, we consider delisting-related variables denoted by $\mathrm{DL}$, which are discussed later.

\section{Filters and Cleaning}

After loading the data, we perform a few filters and cleaning procedures. In particular, we keep common shares, those with 10 or 11 codes. We drop missing values for prices. There are also certain flags for prices denoted by $-44,-55,-66,-77,-88$, and -99 . We drop these from the data as well. Additionally, we keep securities listed on major exchanges (NYSE, AMEX, or NASDAQ). Given these filters, we compute the market cap for each stock-month in the data.

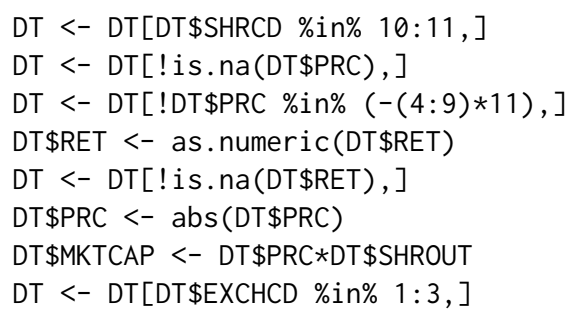

There may be duplicates in the data depending on the identifier of interest. To control for this, consider the following commands:

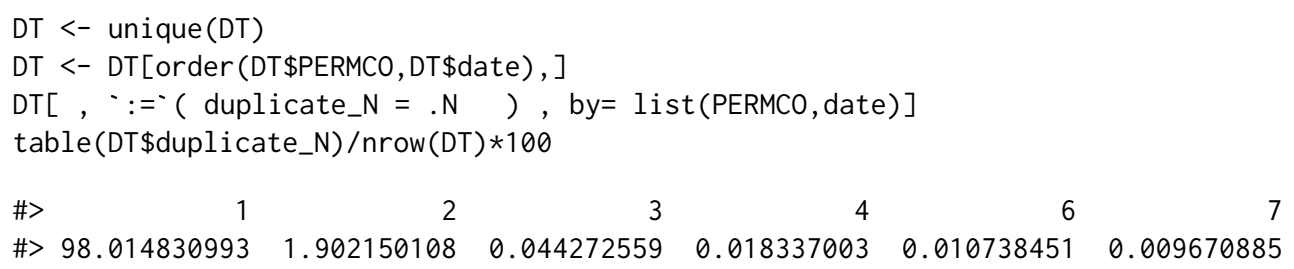

Note that the := command creates a new variable to the already existing data.table, where .N denotes the data length. By grouping the data based on the stock identifier and month, we can count whether there are multiple observations within each case. As we observe from the above table, about $2 \%$ of the observations are duplicates, i.e., multiple observations for the same stock-month. For instance, the table below illustrates the case in which we have 7 duplicates:

\begin{tabular}{|c|c|c|c|c|c|c|c|c|c|}
\hline \#> & PERMCO & date & & & COMNAM & SHROUT & SHRCD DLRET & DLSTCD & DLPDT \\
\hline \#> 1: & 54311 & 20160531 & LIBERTY & MEDIA CORP & 3RD NEW & 25569 & 11 & NA & NA \\
\hline \#> 2: & 54311 & 20160531 & LIBERTY & MEDIA CORP & 3RD NEW & 55684 & 11 & NA & NA \\
\hline \#> 3: & 54311 & 20160531 & LIBERTY & MEDIA CORP & 3RD NEW & 10228 & 11 & NA & NA \\
\hline \#> 4: & 54311 & 20160531 & LIBERTY & MEDIA CORP & 3RD NEW & 22284 & 11 & NA & NA \\
\hline \#> 5: & 54311 & 20160531 & LIBERTY & MEDIA CORP & 3RD NEW & 102277 & 11 & NA & NA \\
\hline \#> 6: & 54311 & 20160531 & LIBERTY & MEDIA CORP & 3RD NEW & 9871 & 11 & NA & NA \\
\hline \#> 7: & 54311 & 20160531 & LIBERTY & MEDIA CORP & 3RD NEW & 222735 & 11 & NA & NA \\
\hline \#> & EXCHCD & $\mathrm{RE}$ & PRC & CUSIP & MKTCAP & duplica & te_N & & \\
\hline \#> 1: & 3 & 0.06448 & 19.48 & 53122987 & 98084.1 & & 7 & & \\
\hline
\end{tabular}




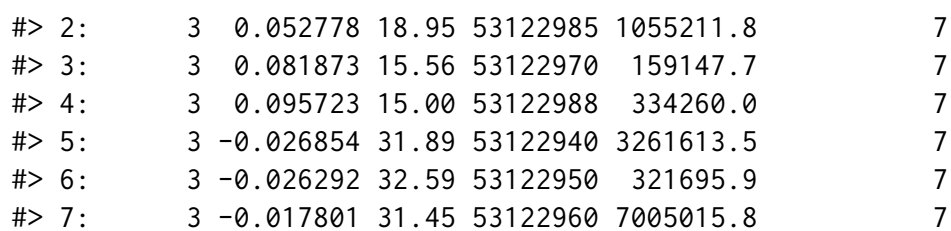

Note that the duplicates arise due to different CUSIP identifiers. Since we are planning to link the data with the COMPUSTAT using CUSIP, we check whether there are duplicates for the same CUSIP-month:

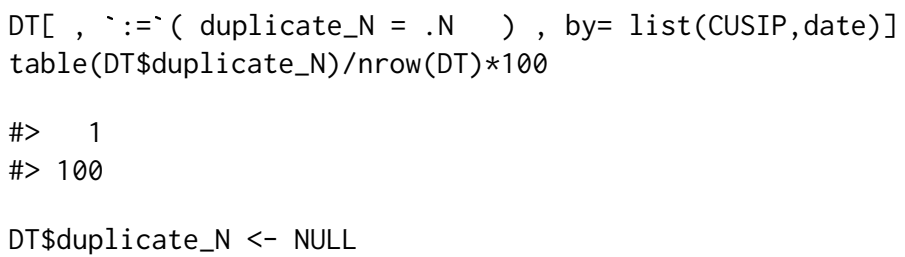

In all cases, observe that there is a unique CUSIP-date observation. However, if one is working with CRSP alone, it is common to aggregate duplicates by value-weighting the observations based on market cap to yield a unique PERMCO-month observation. Additionally, note that the first 6 CUSIP characters result in the same unique identifier.

In terms of date formatting, we utilize the lubridate library to manipulate dates:

DT\$date <- ymd(DT\$date)

DT\$date <- ceiling_date(DT\$date, "m") - 1

It is common to require a minimum history of each security in the data. For instance, a researcher may need to estimate the market beta on a rolling window using an initial sample of 2 years. For the sake of illustration, we require that each security should have at least two months of data (2 observations). Nonetheless, dropping observations in the following manner could have major implications in terms data-snooping and survivor-ship bias. In Section 2.4, we discuss the sensitivity of the portfolio results to this input.

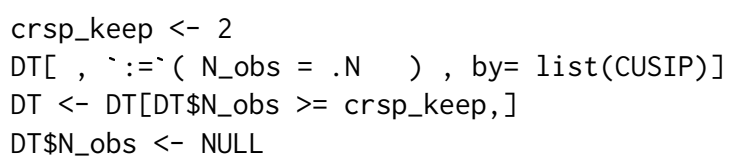

Finally, we have 24,581 unique securities, 720 months, and a total of 3,184,762 security-month observations.

\section{Delisted Returns}

An important characteristic of the CRSP database is that it includes historical companies that were delisted in the past. Not controlling for such delisting creates a survivor-ship bias, especially when it comes to researching the cross-section of stock returns - see, e.g., Beaver et al. (2007) for further information. To control for delisted returns, we follow the methodology recommended by Bali et al. (2016). We demonstrate these steps below. Before we do so, we take a quick look at the summary statistics of the current monthly returns:

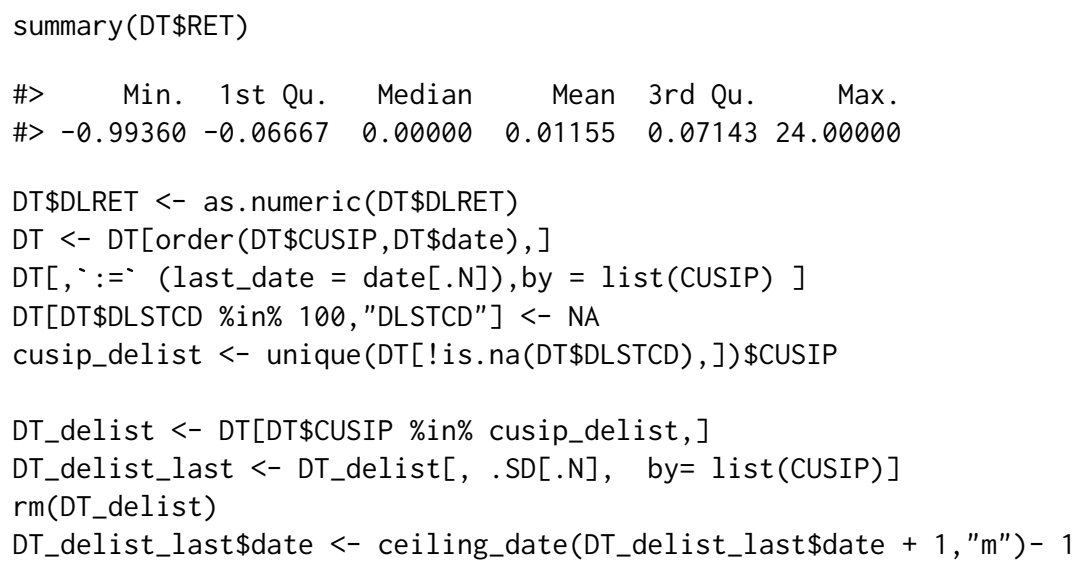




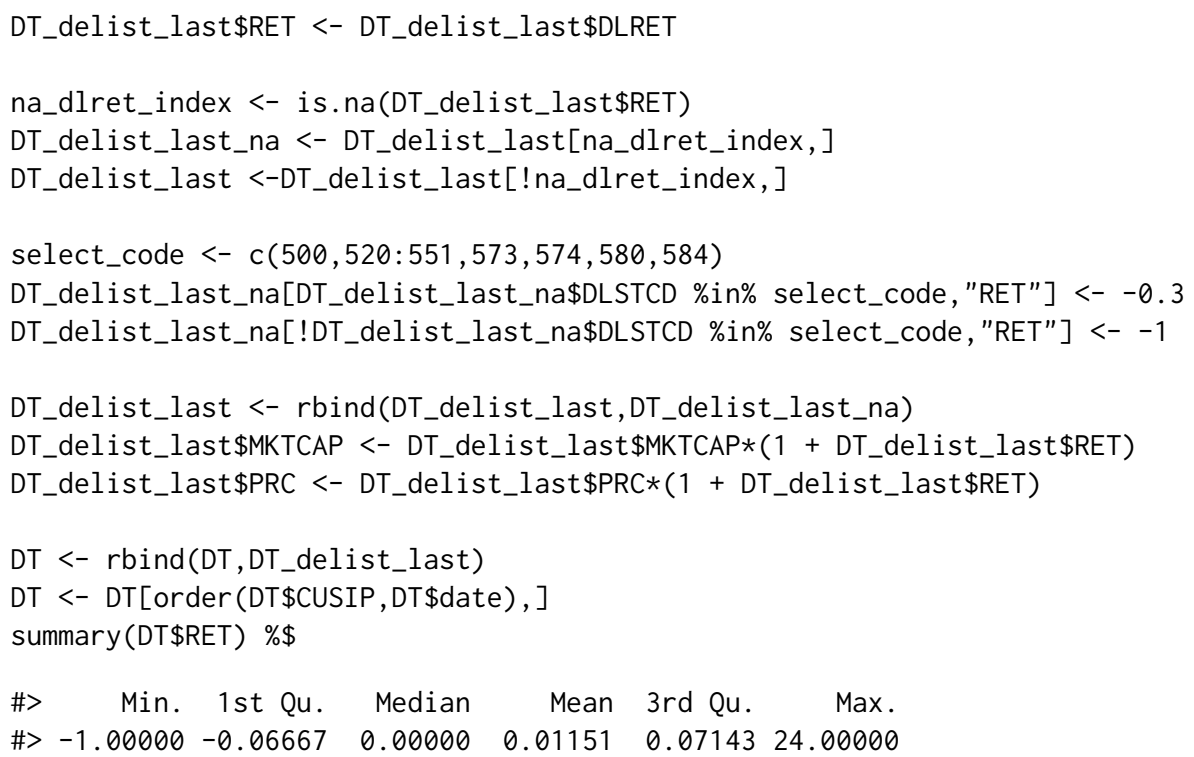

The above steps adjust for delisted returns. When available, it takes into consideration the delisting returns provided by CRSP. Otherwise, we use an arbitrary return according to the suggestion by Bali et al. (2016). We can see that the minimum return becomes $-100 \%$. However, at the same time, we observe that the mean return stays roughly the same due to the large sample size. It is also worth mentioning that dropping stocks below a certain price level potentially eliminates outliers and penny stocks that are more likely to get delisted.

\section{Simple Portfolio Formation}

Before we merge CRSP with COMPUSTAT, let us perform some basic analysis. For instance, we can easily aggregate the security return on the monthly level to create either a value-weighted or equally weighted portfolios. To do so, consider the following commands:

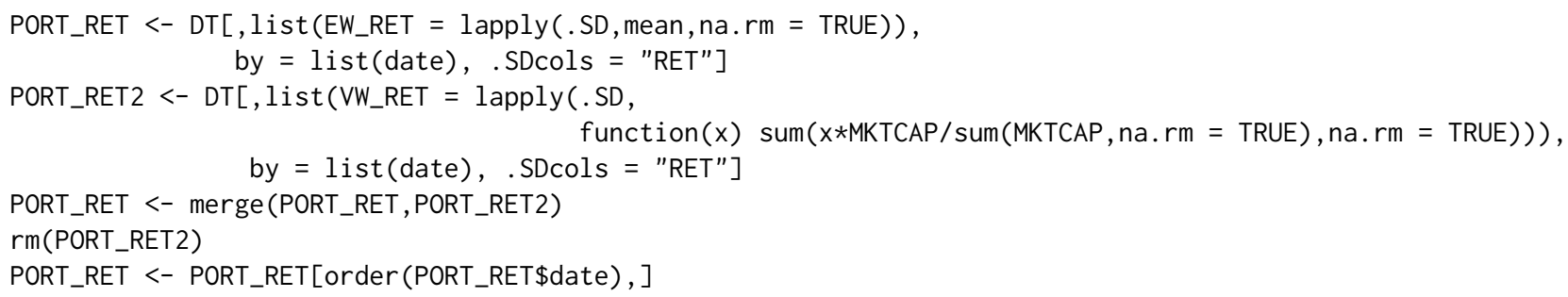

To summarize the returns over time, consider the time series of cumulative returns for each portfolio. We refer to the ggplot2 library and the National Bureau of Economic Research (NBER) recession periods to do so:

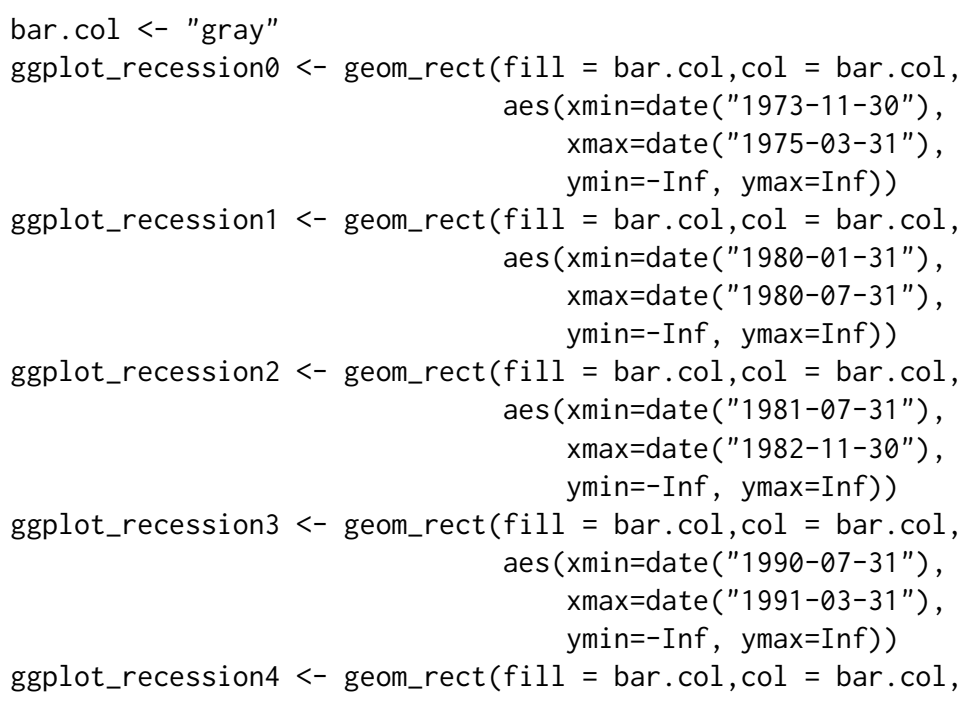


Figure 1: This figure demonstrates the cumulative return of equally-weighted (red line) and valueweighted (blue line) portfolios over time. The gray bar denote the recession periods according to the National Bureau of Economic Research (NBER).
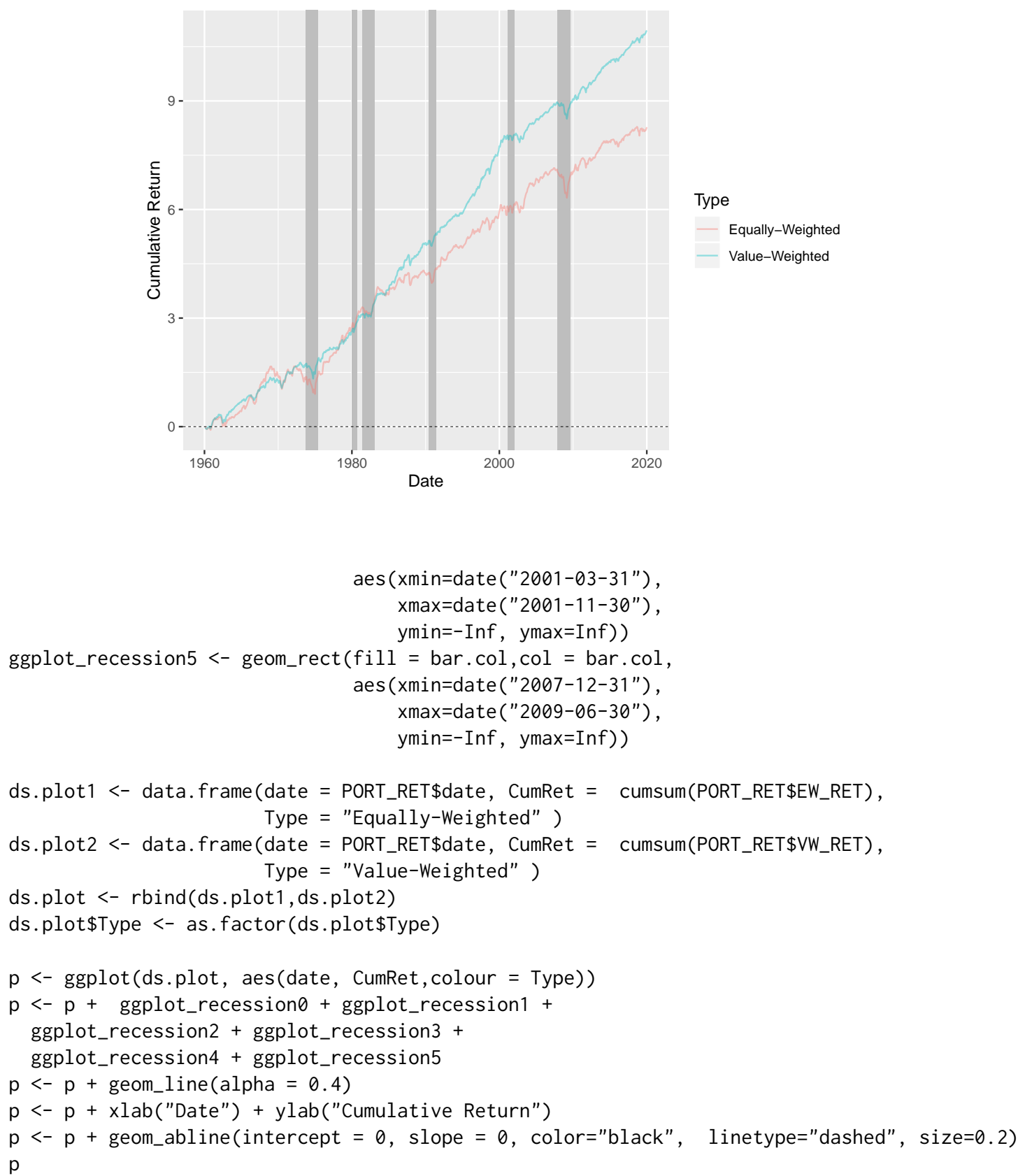

We note that, overall, the equally-weighted portfolio under-performs the value-weighted one. The equally-weighted portfolio attributes greater weight to small-cap stocks. Contrary to Fama and French (1993), interestingly, we observe that the value-weighted stocks outperform the small-cap stocks. Nonetheless, the pattern became evident beginning in the late $80 \mathrm{~s}$. To take a closer look at the above, we group securities into size portfolios. At each month, we group securities into 5 groups based on the market cap cut-off. ${ }^{2}$ To perform the cut-off, we refer to the ntile function from the dplyr library. In the following analysis, we proceed with equal-weighting for the sake of brevity.

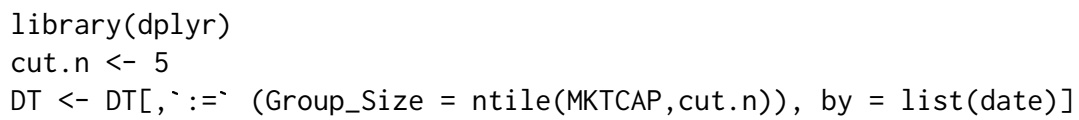

\footnotetext{
${ }^{2}$ Note that in empirical asset pricing studies, when forming portfolios based on a single characteristic (i.e., single-sort), the common practice is to choose $G=10$. On the other hand, for double-sorting it is common to choose $G=5$. This, however, depends on data availability. In our case, we choose $G=5$ for both brevity and consistency (see, e.g., Fama and French (1993)).
} 
N_G <- DT[, .N, by = list (date,Group_Size) $]$

N_G[, mean $(N)$, by = list(Group_Size) $]$

$\begin{array}{lrr}\text { \#> } & \text { Group_Size } & \text { V1 } \\ \text { \#> 1: } & 2 & 885.3694 \\ \text { \#> 2: } & 1 & 885.7667 \\ \text { \#> 3: } & 3 & 885.3875 \\ \text { \#> 4: } & 4 & 885.3694 \\ \text { \#> 5: } & 5 & 884.9500\end{array}$

We observe that, on average, each group contains 885 firms over the sample period. In addition to the group size, we consider the next one month return on each security. We use the shift function from data.table and apply it to each security as follows:

DT <- DT[order(DT\$CUSIP, DT\$date), ]

DT <- DT[ , : :-' (RET_1 = $\operatorname{shift}($ RET,-1$))$, by $=\operatorname{list}($ CUSIP $)]$

Given the above, we report summary statistics on the size group level:

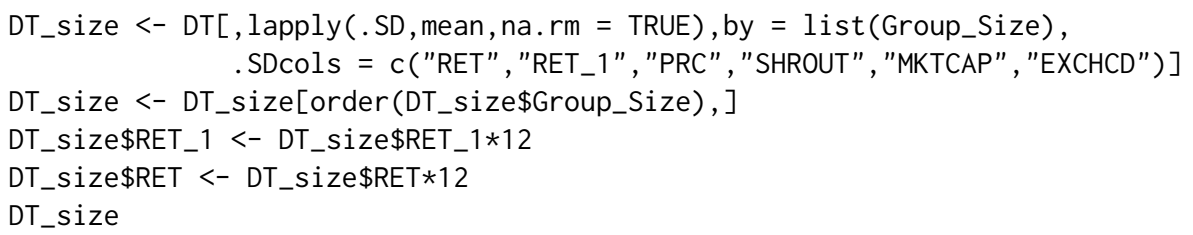

Clearly, securities ranked in the 5th largest size group have a higher market-cap, which is associated with higher prices and shares outstanding. Additionally, note that the large stocks are more likely to be listed on NYSE (EXCHCD = 1), whereas the small-cap stocks are listed on NASDAQ $(\mathrm{EXCHCD} \mathrm{=3).}$ In terms of returns, the results are sensitive with respect to whether we consider an in-sample return or next month's return. In the in-sample, we observe that large-cap outperform small-cap. Nonetheless, the more relevant case in practice is the out-of-sample return. In the latter case, we observe that small-cap stocks outperform large-cap stocks. In annual terms, the small-cap stocks return 10\% higher mean return than large-cap stocks. Ignoring transaction cost and assuming that investors rebalance their portfolios on a monthly basis, this evidence is consistent with Fama and French (1993)'s size premium. That is, investors expect a higher return for investing in small-cap stocks.

\section{COMPUSTAT}

The above discussion relates to the CRSP data alone. In the following, we focus on the COMPUSTAT data, which contains accounting-related information for public firms. Similar to the above, we focus on a subset of variables. For identification, we look into the CUSIP and the CIK number. The latter is relevant to identify firms via the SEC EDGAR system - for those interested in merging the data with SEC filings and perform textual analysis. The FYEARQ and FQTR are the fiscal year and quarter of the data point. For accounting variables, we consider total assets (atq), net income (niq), and common equity ceqq.

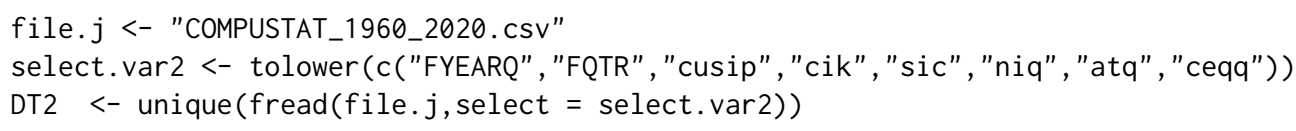

\section{Filters and Cleaning}

To link between COMPUSTAT and CRSP, we need to make a small adjustment for the CUSIP identifiers. In CRSP, the number of characters is 8 , whereas in COMPUSTAT, it is 9.

table (nchar (DT\$CUSIP)) 


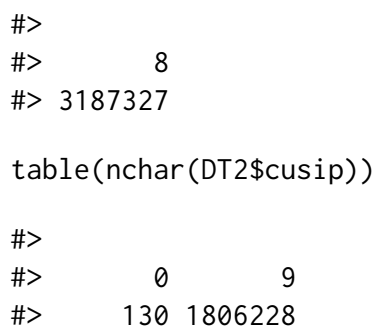

Note that there a few cases in which the CUSIP is unavailable in COMPUSTAT. The adjustments are described below:

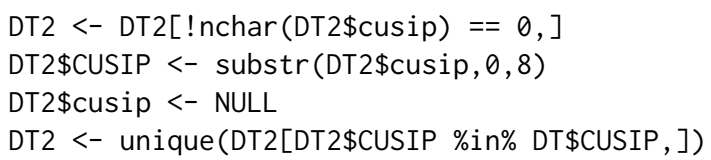

In order to merge with the CRSP data, which corresponds to calendar dates, we adjust the fiscal dates in COMPUSTAST. It is common to use 6 months lags to allow the financial disclosures to become publicly available. To do so, we perform the following adjustments:

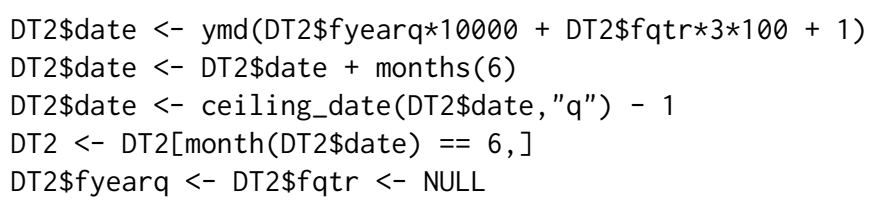

Additionally, we keep the annual data rather than the quarterly one and consider portfolio formation on an annual basis. ${ }^{3}$ In particular, we keep the June data for the portfolio formation process.

Same as before, let us check for duplicates:

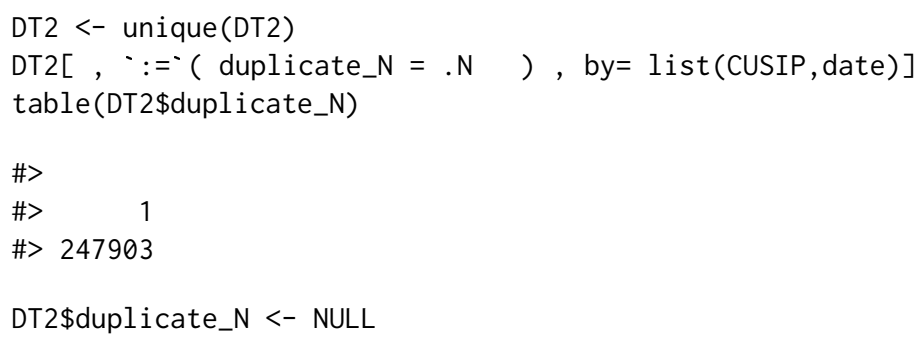

The COMPUSTAT dataset have unique CUSIP-date observations.

\section{Summary Statistics}

Given the final COMPUSTAT data, we consider a few summary statistics for each industry, which is defined using the 4 th digit of the SIC code.

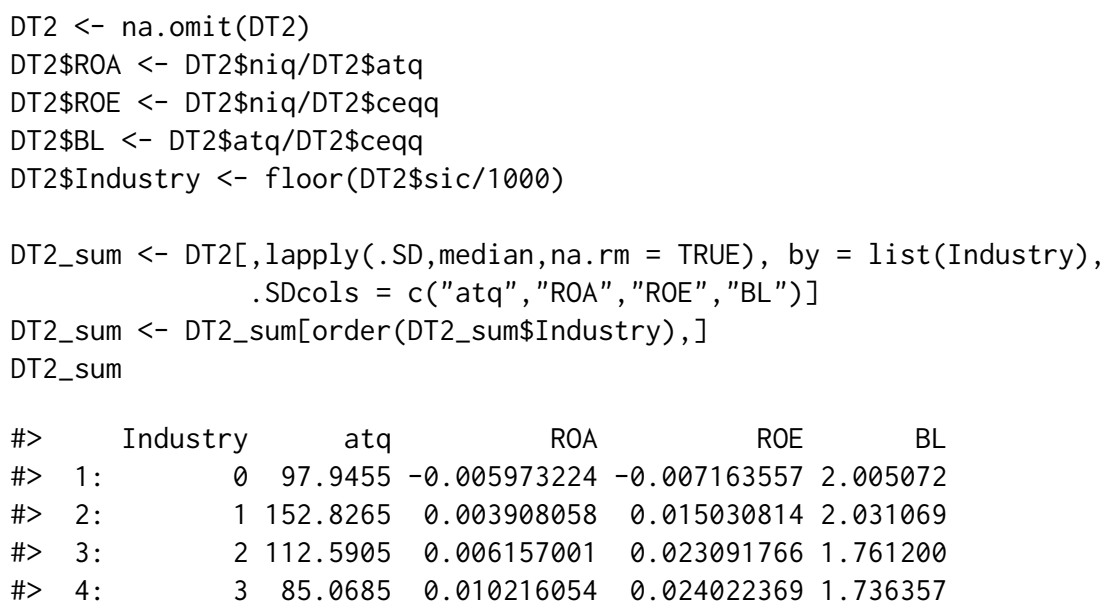

${ }^{3}$ Clearly, it all depends on the purpose of the investigation. 
Figure 2: This figure below demonstrates the concentration in the financial industry. It illustrates the book value of assets held by the top $10 \%$ banks relative to the total assets held by the financial industry.

\section{Proportion of Assets held by Top 10\% in Financial Industry}

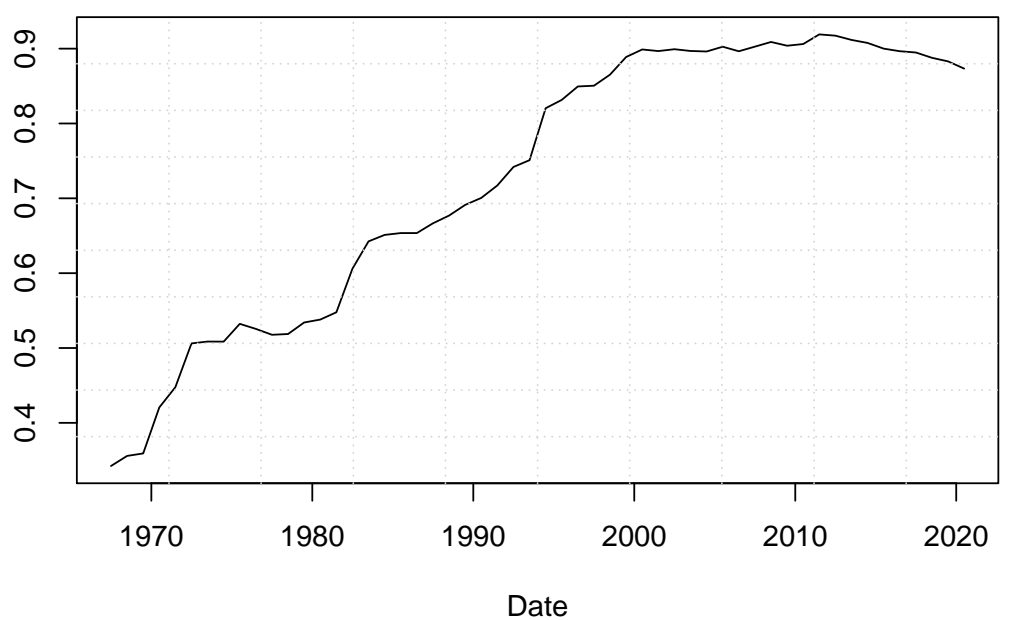

\begin{tabular}{|c|c|c|c|c|c|}
\hline \#> & 4 & 540.3000 & 0.006908974 & 0.024877318 & 2.914309 \\
\hline 6: & 5 & 148.0990 & 0.011941449 & 0.030180501 & 2.155898 \\
\hline 7: & 6 & 893.6370 & 0.002491525 & 0.026317412 & 8.96 \\
\hline 8: & 7 & 88.5455 & 0.004830920 & 0.018396345 & .7 \\
\hline 9: & 8 & 73.5180 & 0.006937877 & 0.020926220 & 1.904 \\
\hline 10: & 9 & 37.3550 & -0.003438435 & 0.006888589 & 1.562 \\
\hline
\end{tabular}

We observe that financial firms are associated with the highest book leverage, given the business nature of financial institutions. Also, we note that the financial industry is associated with the largest total assets. This is not surprising given the concentration of the financial industry over time, in which a few entities hold the majority of assets. To relate to the last point, consider the total assets of the top $10 \%$ firms with respect to the total assets in the industry as a whole.

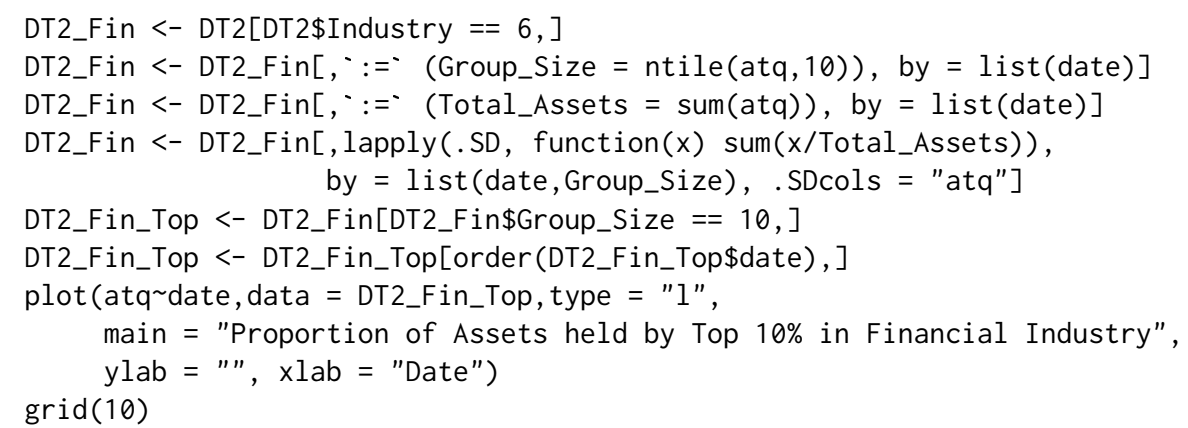

According to Figure 2, we discern that the top 10\% increased their share of total assets from $34 \%$ in the late 60 s up to $90 \%$ more recently.

\section{CRSP-COMPUSTAT}

Note that the COMPUSTAT dataset is annual, while the CRSP is monthly. If we seek to form portfolios based on book-to-market (BM) ratio, such as the case for Fama-French, we need to create an annual $\mathrm{BM}$ variable in the COMPUSTAT dataset. Before we merge the data altogether, let us add the market value of equity (ME) to the COMPUSTAT dataset. Additionally, we add the stock prices which would be useful for small-cap stocks from the portfolio formation later on.

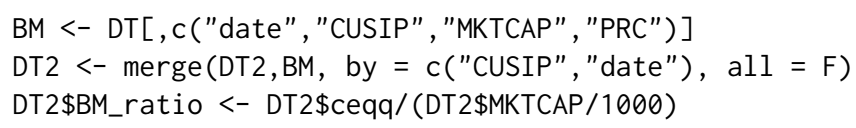




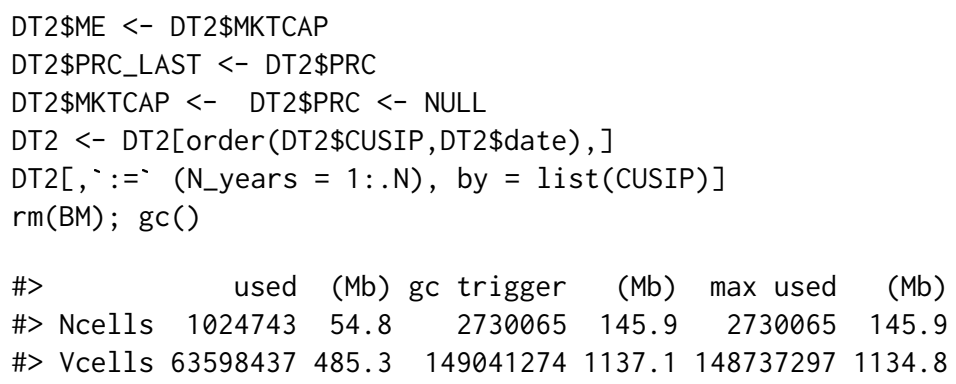

The above commands link the COMPUSTAT and the CRSP datasets to determine the market equity of the firms and, hence, the book-to-market ratio. Also, we denote the stock price as PRC_LAST to refer to the recent stock price in the annual data.

Before we finally merge the data altogether, we need to do one small trick with the CRSP data. The ultimate goal of this illustration to attribute the next 12 months' returns with respect to the BM ratio from the previous June. To do so, consider the following:

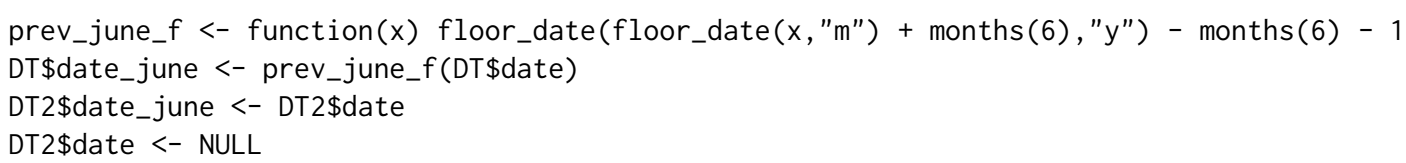

While the prev_june_f seems obscure, one should break the function into different components in order to understand how it works. Consider the special case where we have:

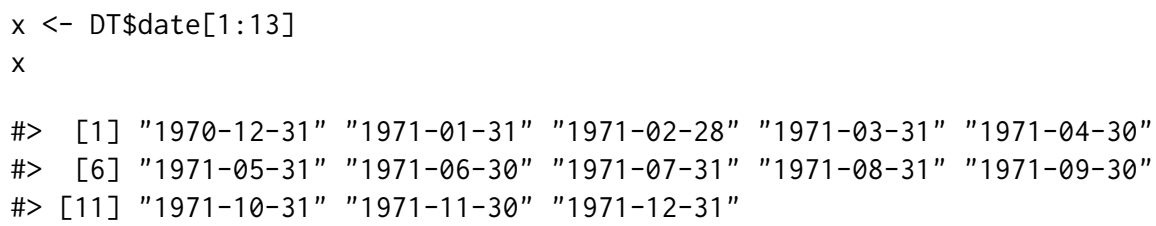

The first command of the function shifts the dates six months ahead:

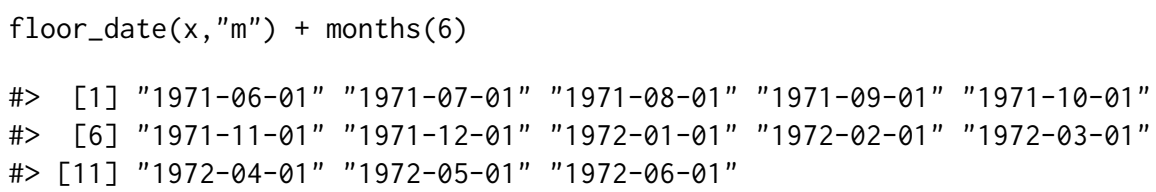

The second step identifies the floor of each date on the annual level:

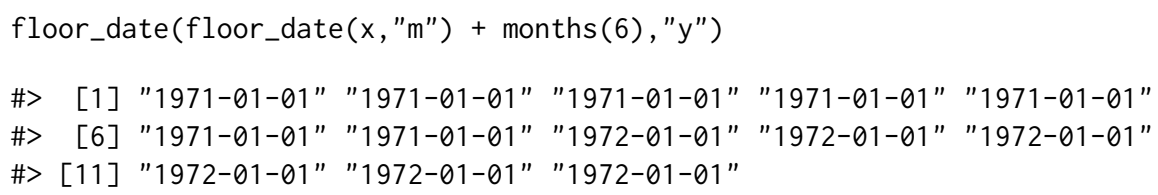

The final step subtracts 6 months to identify the June of the previous year. The minus one is added to retrieve June 30th rather than July 1st, such that:

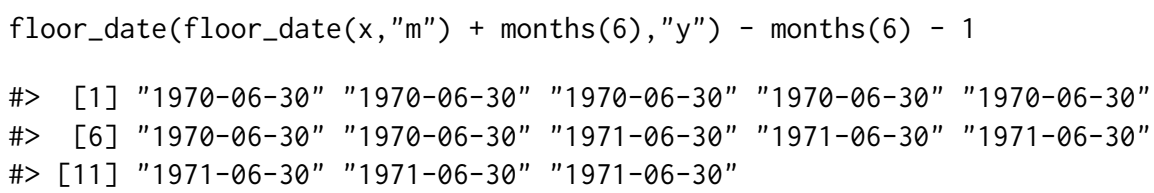

Looking at returns between Dec 1970 and Mar 1971, the function traces these observations back to June 1970 for the first 7 returns. When the next June data shows up, the date_june variable adjusts accordingly. Finally, the merged dataset is given by:

DT12 <- merge(DT, DT2, by = c("CUSIP", "date_june"))

Note: The above steps provide details on how to merge between the two data sets. In Figure 3, we provide a flow chart summarizing the steps/processes undertaken to develop the final merged data set DT12. 
Figure 3: The figure below illustrates a flow chart of the data merging process. It demonstrates the steps taken altogether to come up with the final CRSP-COMPUSTAT merged data set.

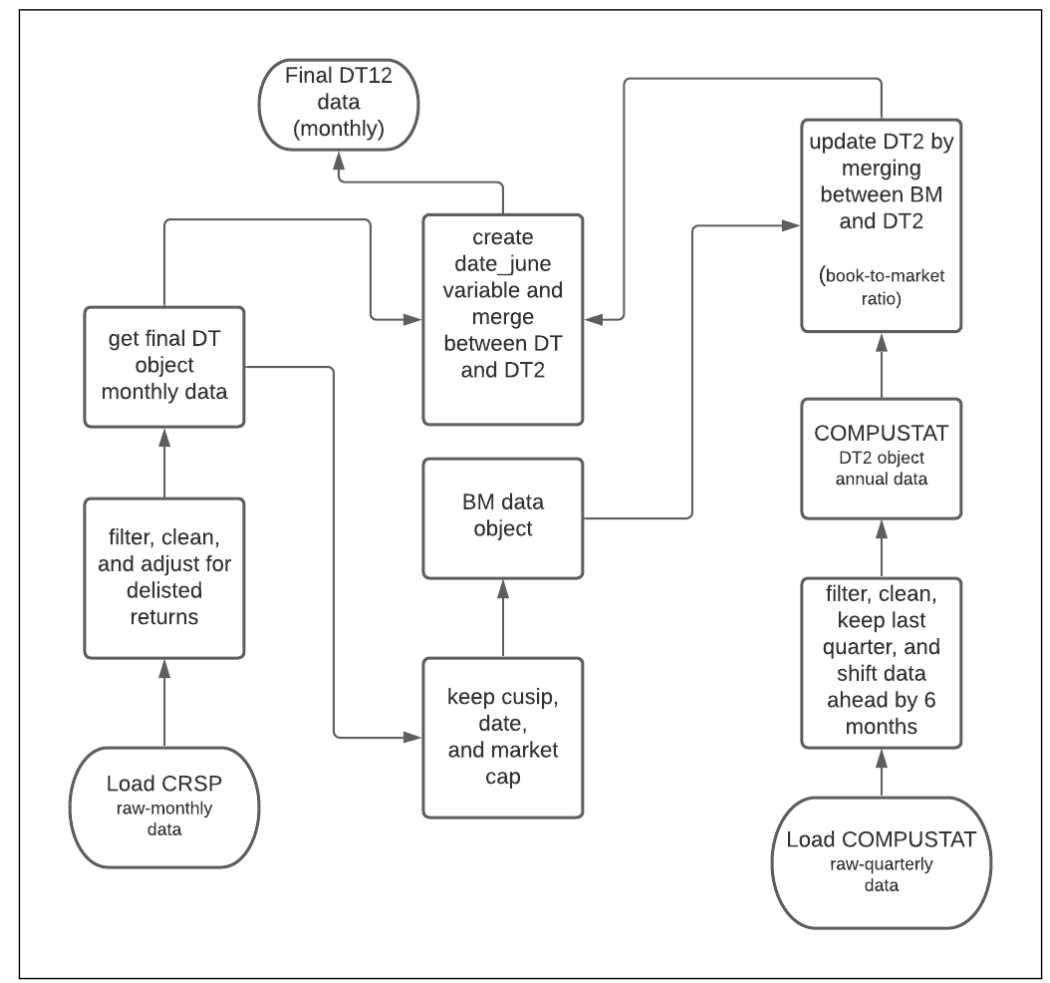

\section{Forming Size and BM Portfolios}

The DT12 object contains the final CRSP-COMPUSTAT data. The merging is conducted to allow for portfolio formation at the end of June each year, as mentioned above. Such a setting allows a convenient way to form portfolios without relying on loops. Nonetheless, it would also impose that portfolio managers balance their portfolios on a monthly basis according to the market cap from the previous June.

Given the merged dataset, we form groups at the end of June-year based on market equity (size) and book-to-market ratio (value):

DT12 <- DT12[, : := (Group_ME = ntile $(M E, 5))$, by = list (date_june) $]$

DT12 <- DT12[, : :-'(Group_BM = ntile $($ BM_ratio,5)), by = list(date_june,Group_ME) $]$

The above two commands perform dependent portfolio sorting, in which firms are first sorted based on size and then on BM ratio. We consider value-weighting to compute the future returns on each size-value portfolio. This results in 25 value-weighted portfolios.

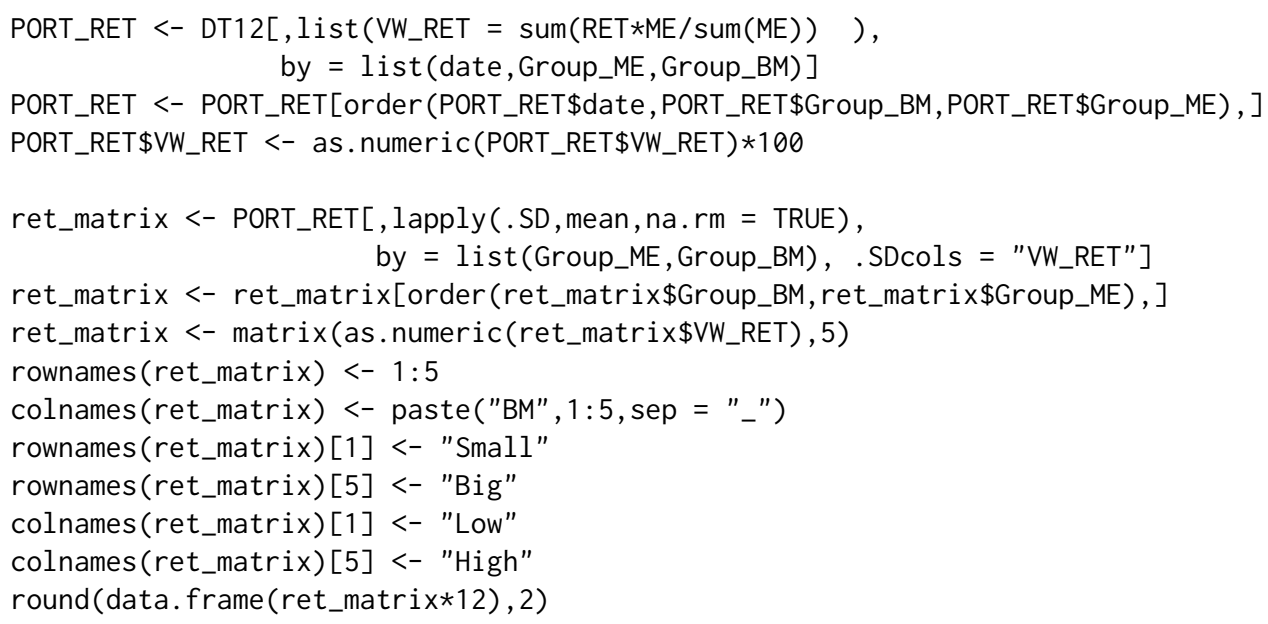




$\begin{array}{lrrrrr}\text { \#> } & \text { Low } & \text { BM_2 } & \text { BM_3 } & \text { BM_4 } & \text { High } \\ \text { \#> Smal1 } & 12.93 & 14.73 & 18.05 & 20.14 & 23.40 \\ \text { \#> 2 } & 8.45 & 12.55 & 14.37 & 16.72 & 16.17 \\ \text { \#> 3 } & 8.04 & 11.79 & 14.30 & 14.24 & 15.99 \\ \text { \#> 4 } & 9.89 & 11.53 & 11.92 & 14.47 & 14.77 \\ \text { \#> Big } & 9.84 & 11.70 & 10.41 & 13.13 & 12.78\end{array}$

For each column above, we observe the stock returns (raw) decrease, on average, with size. This is commonly known as the size effect. At the same time, we observe that within each size group, the mean return increases with the BM ratio. The latter denotes what is known as the value effect. In other words, investors expect higher returns from small enterprises and undervalued stocks (trading below book value). Nonetheless, recent discussions debate whether this is the case. For further information on this, see this article.

\section{Risk-Adjusted Returns using Fama-French's Risk Factors}

The above portfolio results compute the raw returns. In order to price these portfolios, we decompose the returns into (1) systematic components (risk-premiums) and (2) non-systematic. The latter denotes the risk-adjusted returns. Additionally, we consider the excess return on each portfolio, i.e., the portfolio return minus the 1-month Treasury yield.

The Fama-French's risk factors are obtained easily using the Kenneth French public library according to the commands below. Note that we focus on the three factors: market, size, and value:

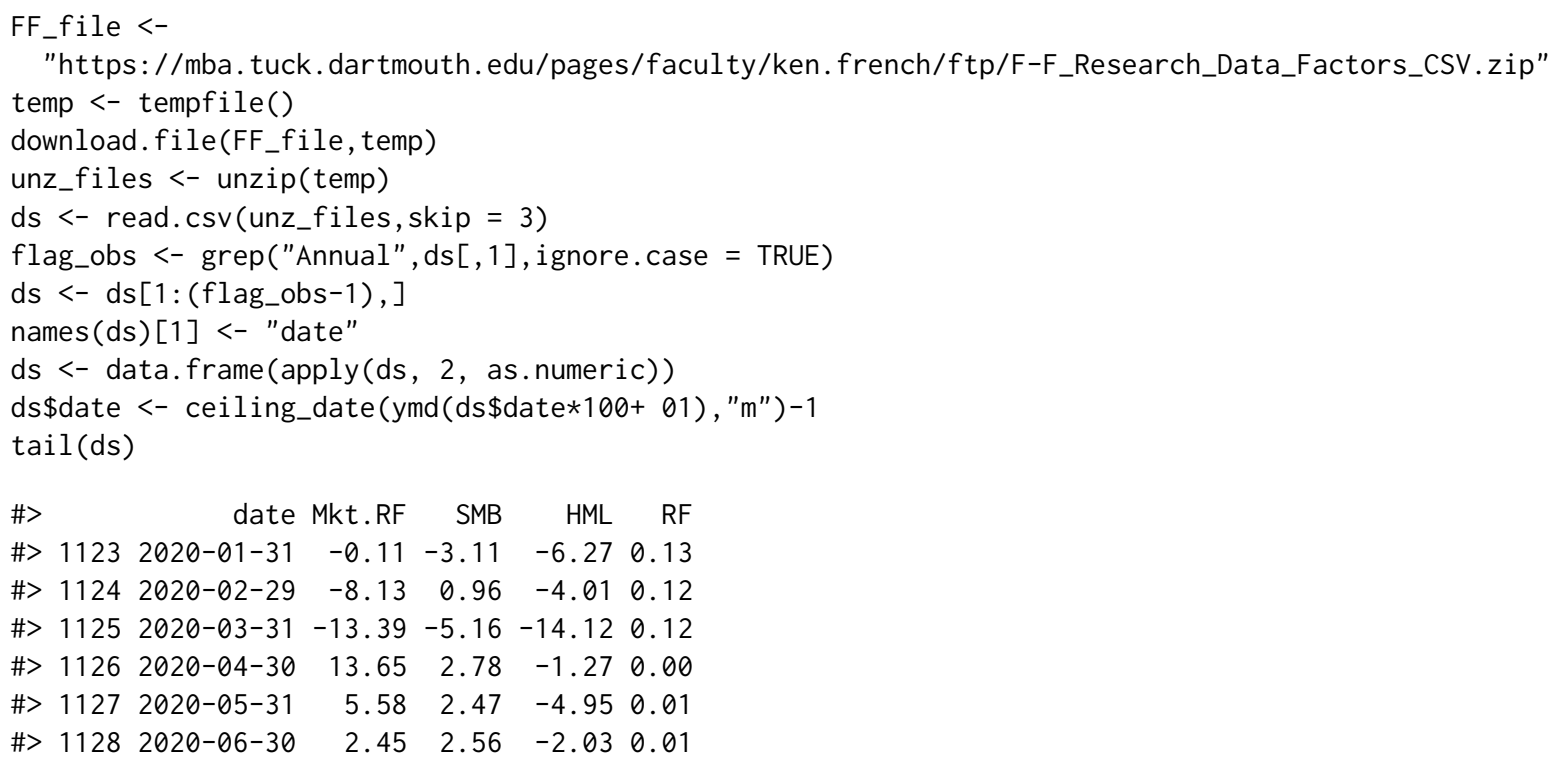

We merge the risk factors data with the portfolios time series and regress the excess returns of each of the 25 portfolios on the three factors. To do so, we leverage some functional programming using the lapply base function along with the dlply function from the plyr library as follows:

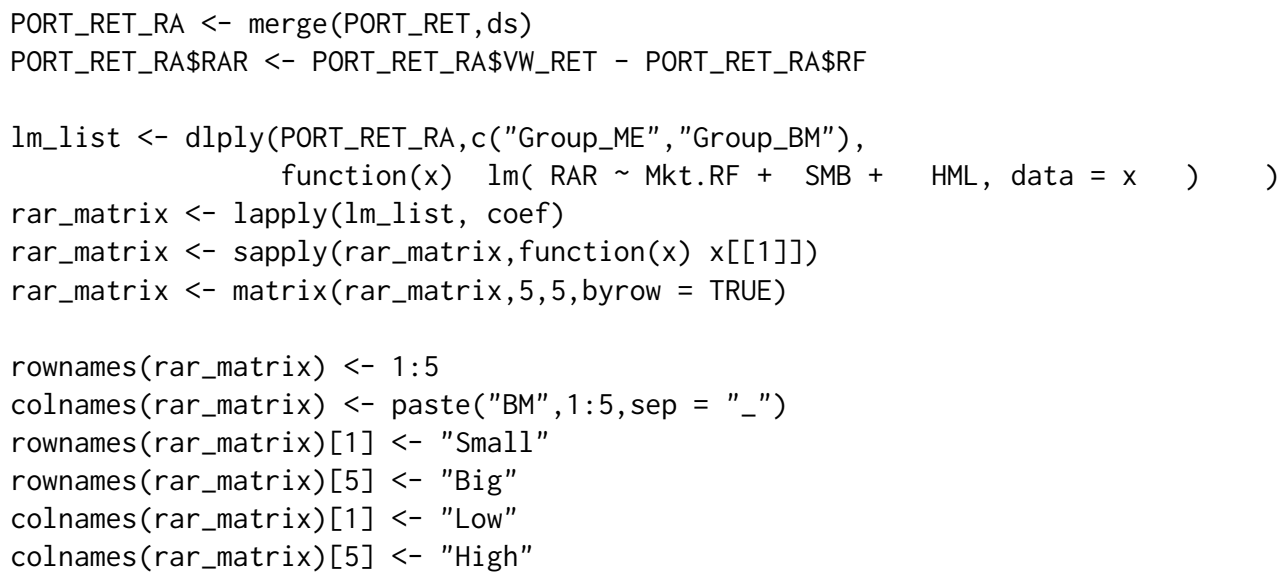




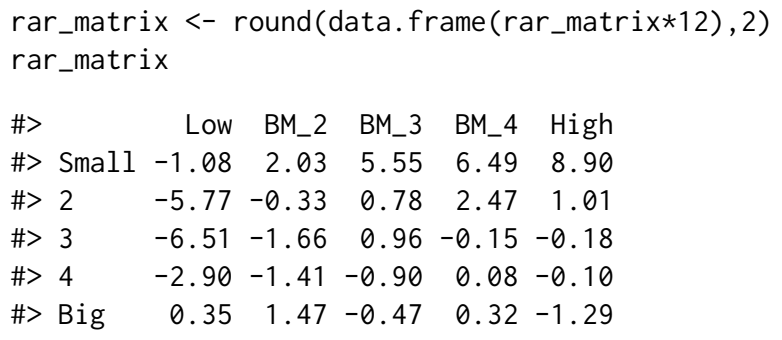

Note that after controlling for the three risk factors, the high-small portfolio still yields an annual return of $9 \%$. A potential argument may be that such alpha is attributed to other risk factors that the three-factor model does not fully price. More recently, Fama-French suggest five factors model to better representation of systematic components (Fama and French, 2015).

\section{Rendering Results}

The above results are subjected to certain filtering, the time period, and the number of months each stock should include in the data. One major challenge is whether the securities in the analysis are tradable. For instance, it is common to consider stocks with a price larger than $\$ 5$. The major issue with doing so is that such a filter could cause a forward-looking bias. By the time the decision maker allocates his/her portfolio, he/she cannot ascertain whether the stocks would be above or less than $\$ 5$ in the future - this is less of an issue for large-cap stocks. Hence, to keep stocks that satisfy a minimum price level, it should be done on a recurring basis. Specifically, rather than dropping all observations in which the price is less than $\$ 5$, one should consider only the stocks that were qualified by the time of the portfolio formation. The same issue applies to the window length for which the data is available and other filters one may be interested in controlling for.

The following is a generalized portfolio formation function that takes four arguments. The first two correspond to the minimum price and number of years that the stock should have to be considered investable in June each year. The other two arguments set the time period during which the researcher is interested in computed the mean returns. The function returns a list containing the raw and risk-adjusted returns of the 25 portfolios along with the average number of stocks within each portfolio.

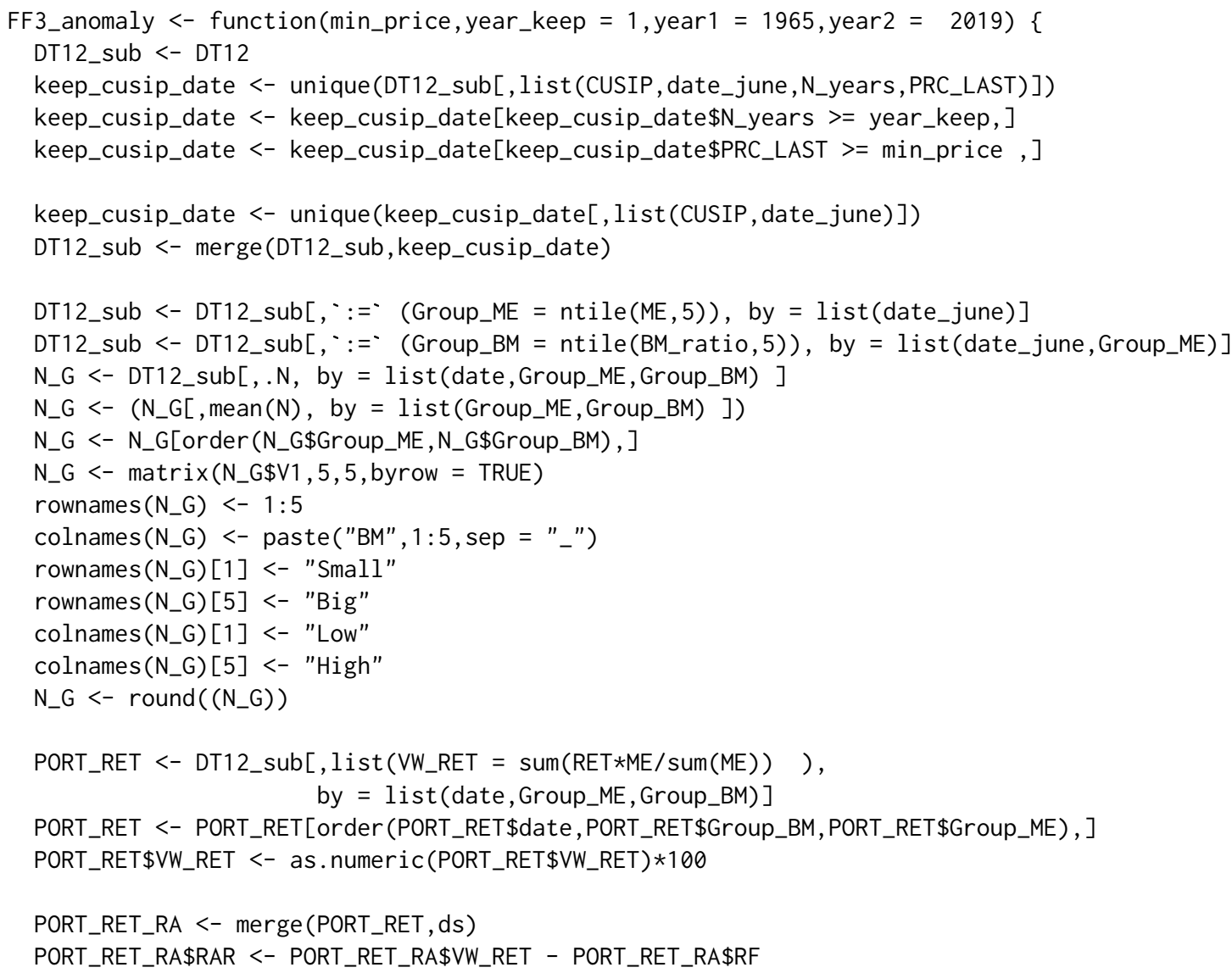




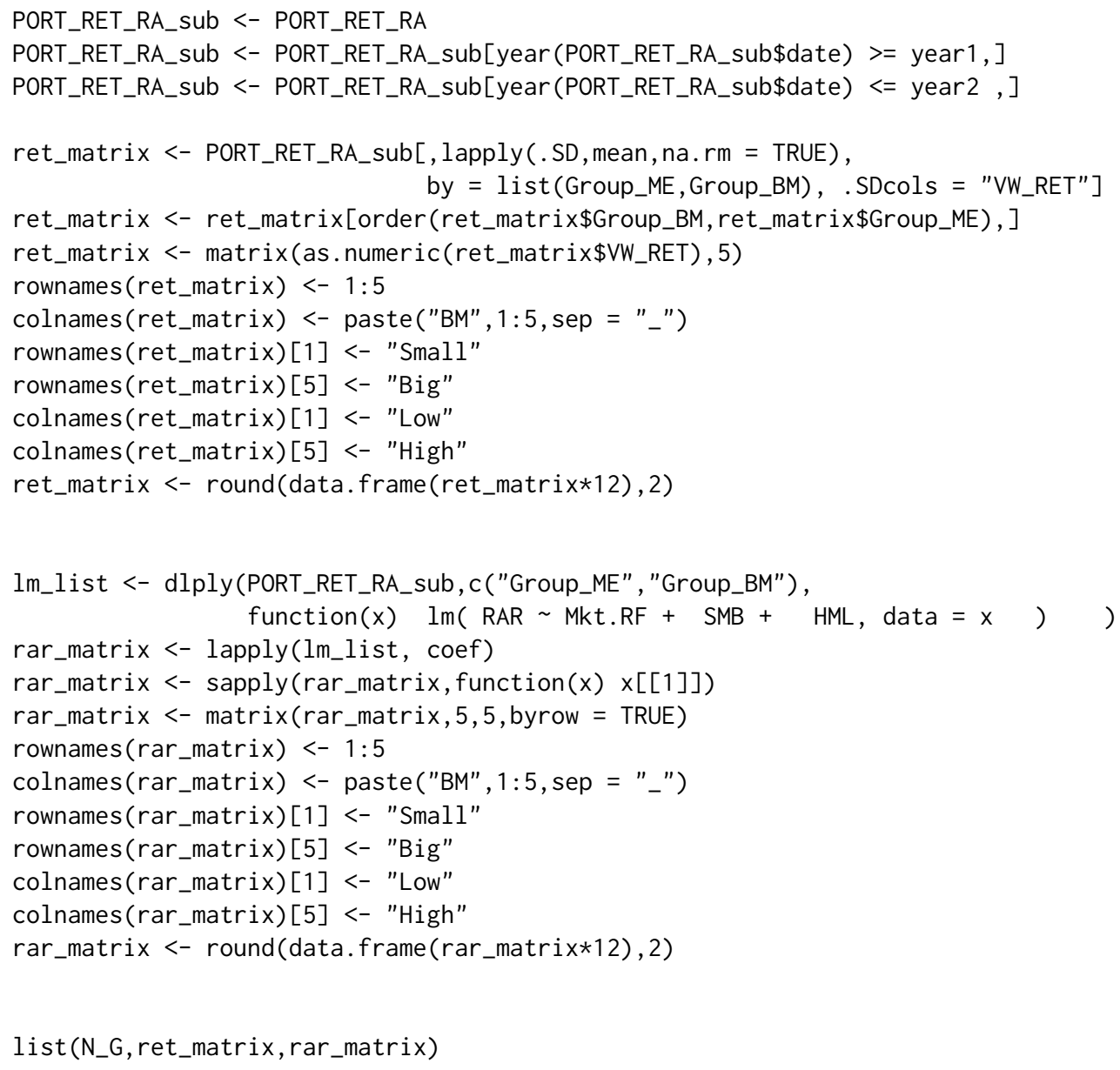

\section{Control for Minimum Price}

Given the above function, we test the sensitivity of the size/value premiums by including stocks with pre-specified minimum price. In particular, we run this for a sequence of prices ranging between 0 and $\$ 50$. With the parallel library, we can easily perform parallel computing on four cores. It takes a few seconds to run the following commands ${ }^{4}$ :

p_seq $<-0: 50$

list_port_price <- mclapply (p_seq, function(p) FF3_anomaly (p), mc.cores = 4)

Given the list list_port_price, we extract the result of interest. In this case, we focus on the raw returns. For instance, the first item of this list corresponds to the same results from Section 2.3.

$\begin{array}{lrrrrr}\text { list_port_price[[1]][[2]] } & & \\ \text { \#> } & \text { Low } & \text { BM_2 } & \text { BM_3 } & \text { BM_4 } & \text { High } \\ \text { \#> Small } & 12.93 & 14.73 & 18.05 & 20.14 & 23.40 \\ \text { \#> 2 } & 8.45 & 12.55 & 14.37 & 16.72 & 16.17 \\ \text { \#>3 } & 8.04 & 11.79 & 14.30 & 14.24 & 15.99 \\ \text { \#> 4 } & 9.89 & 11.53 & 11.92 & 14.47 & 14.77 \\ \text { \#> Big } & 9.84 & 11.70 & 10.41 & 13.13 & 12.78\end{array}$

On the other hand, if we consider $\$ 5$ minimum price, we see that the results are tentative depending on the level of entry:

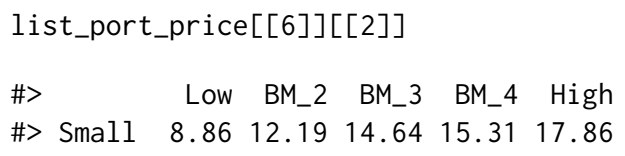

${ }^{4}$ Note that the mclapply can be easily leveraged on Linux machines. 
Figure 4: This figure summarizes the results of the double-sorting portfolio based on the book-tomarket (BM) ratio and size. Stocks are first sorted into five quintiles with respect to the BM ratio. Then, within each BM quintile, stocks are sorted based on size. The double-sorting results in 25 value-weighted portfolios. The $y$-axis corresponds to the value premium, which is the difference between the top and the bottom BM quintiles within a given size group. The $x$-axis controls for the stock's minimum price to be included within each one of the 25 sorted portfolios. The red, green, and blue lines correspond to the size groups of small-cap (1), medium-cap (2), and large-cap (5), respectively. Overall, the plot demonstrates the sensitivity of the value premium as a function of the minimum price.

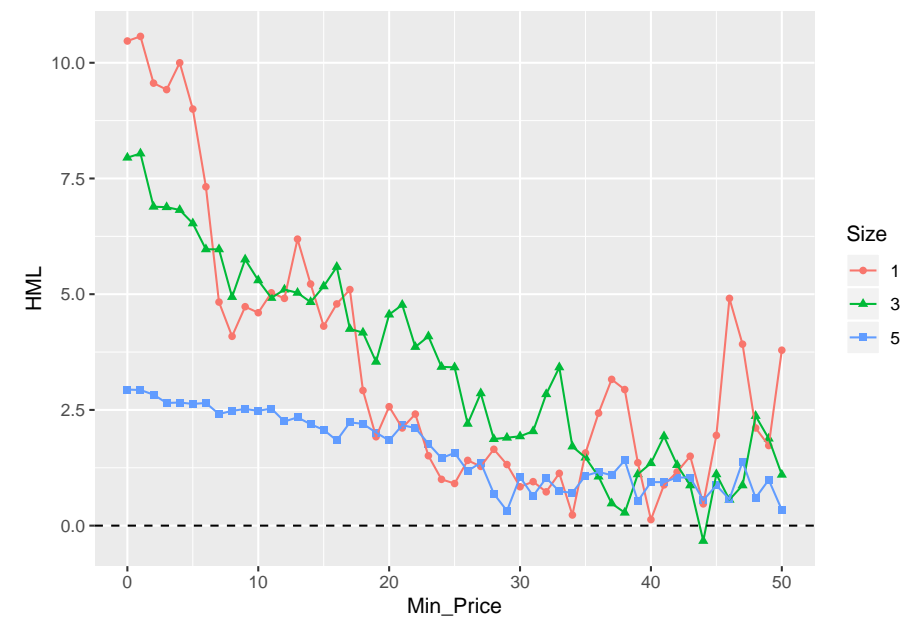

$\begin{array}{lrrrrr}\text { \#> } 2 & 10.35 & 11.94 & 13.51 & 16.18 & 15.08 \\ \text { \#> } 3 & 8.54 & 12.39 & 13.52 & 14.41 & 15.07 \\ \text { \#> } 4 & 10.16 & 11.09 & 11.95 & 14.20 & 15.17 \\ \text { \#> Big } & 9.79 & 11.66 & 10.62 & 12.95 & 12.42\end{array}$

To capture this for each matrix of raw returns, we compute the high-minus-low (HML), i.e., column 5 minus column 1 for each size level. This results in 5 HML premiums for each size level. We summarize the results in Figure 4.

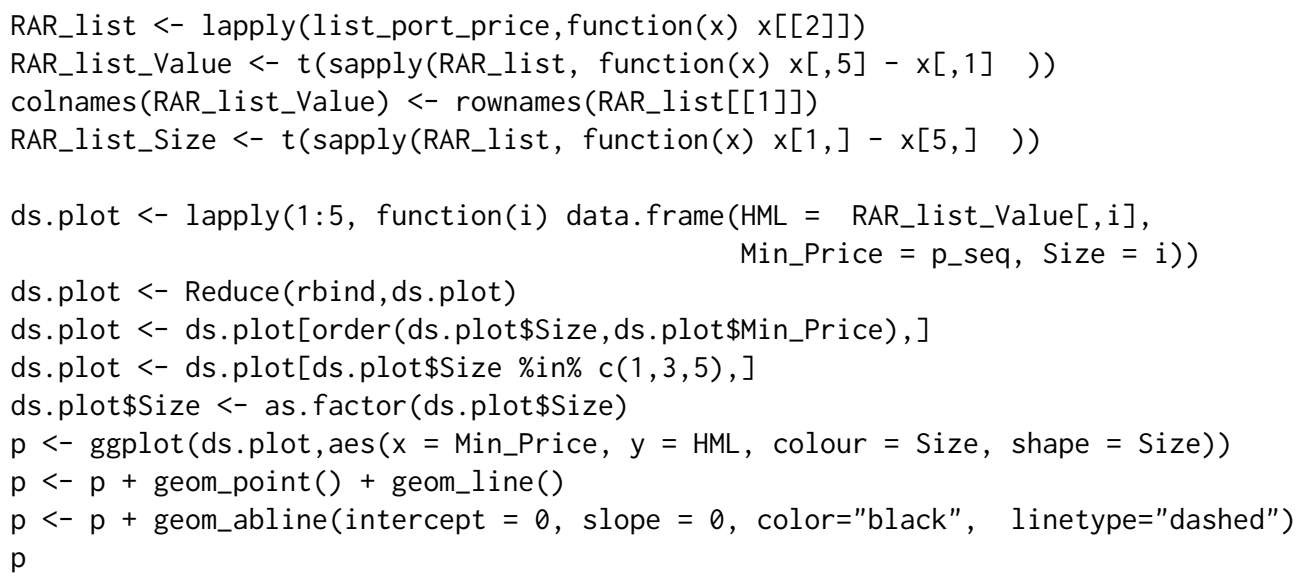

We observe that the HML is more evident for small-cap stocks. However, at the same time, we note that the premium declines as we increase the minimum price entry. One argument is the following. As we increase the minimum price, the size effect is mitigated and, hence, the value premium. On the other hand, this could also be attributed to whether investors can utilize such alphas for small-cap that tend to be less liquid.

We repeat the same plot for the size premium. In particular, we compute the small-minus-big $(\mathrm{SMB})$, i.e., row 1 minus row 5 for each BM level. This results in $5 \mathrm{SMB}$ premiums for each BM group. Similar to Figure 4, Figure 5 demonstrates the sensitivity of the results with respect to the minimum price:

ds.plot <- lapply(1:5, function(i) data.frame(SMB = unlist(RAR_list_Size[,i]), 
Figure 5: This figure summarizes the results of the double-sorting portfolio based on the book-tomarket (BM) ratio and size. Stocks are first sorted into five quintiles with respect to the BM ratio. Then, within each BM quintile, stocks are sorted based on size. The double-sorting results in 25 valueweighted portfolios. The $y$-axis corresponds to the size premium, which is the difference between the top and the bottom size quintiles withing a given BM group. The $x$-axis controls for the stock's minimum price to be included within each one of the 25 sorted portfolios. The red, green, and blue lines correspond to different BM groups of low (1), medium (2), and high (5), respectively. Overall, the plot demonstrates the sensitivity of the size premium as a function of the minimum price.
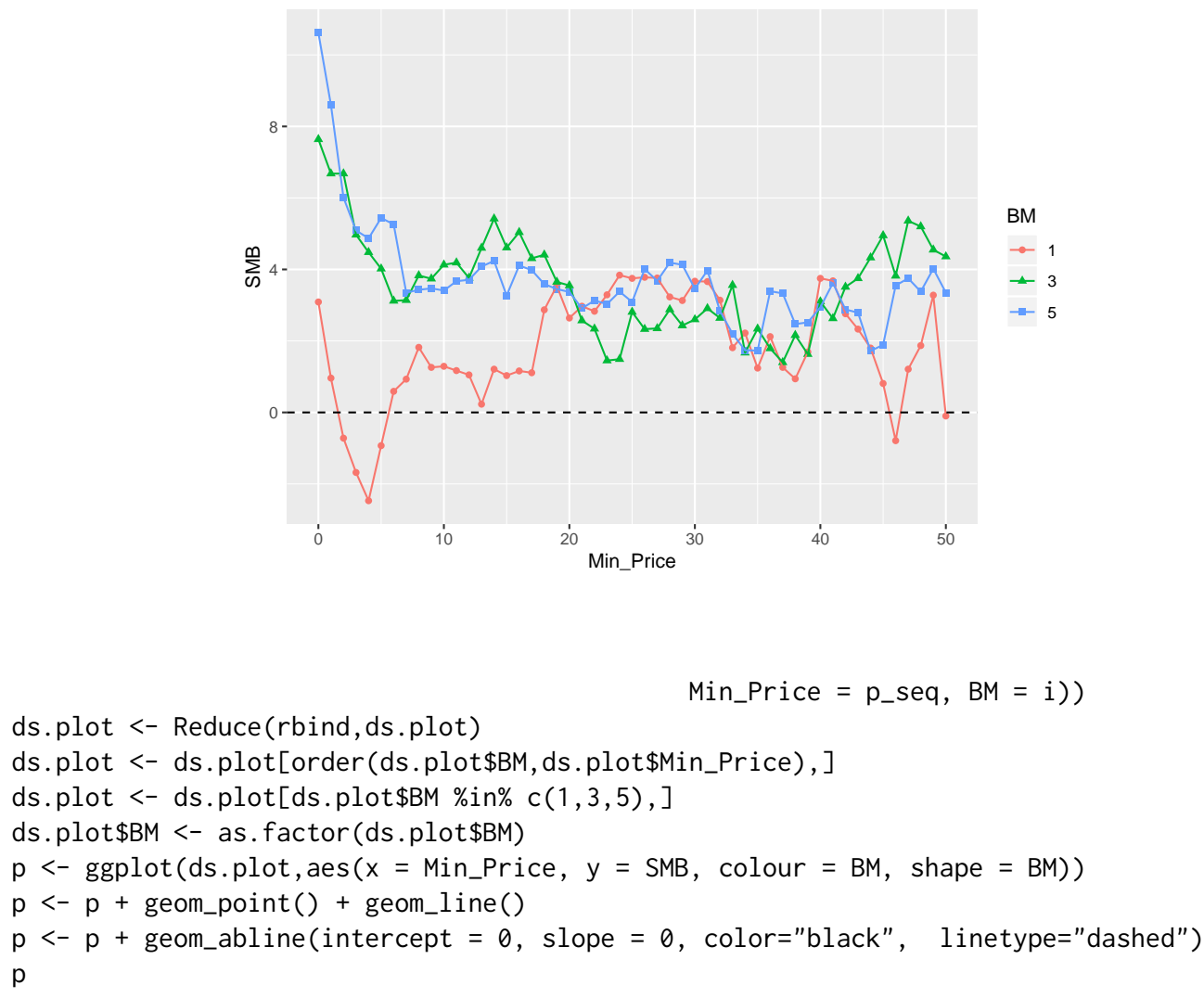

Consistent with the case for the HML premium, the SMB premium seems to shrink as we increase the minimum price entry. While different forces could be attributed to this, it is of great relevance for researchers/investors to understand the mechanisms behind which. Interested readers may find the work by Li et al. (2014) very relevant concerning the impact of liquidity and limits of arbitrage when it comes to the inclusion/exclusion of small-cap stocks.

\section{Additional Results}

We conduct one additional test related to the capital asset pricing model (CAPM) by Sharpe (1964) and Lintner (1965). The following analysis depends only on the CRSP database rather than the merged CRSP-COMPUSTAT data. Hence, the code is executed based on the DT data object only.

The CAPM postulates a positive linear relationship between the market beta (systematic risk) and the asset's mean return. Empirically, a large body of research shows that the relationship is flatter than the one predicted by the model (Jensen et al., 1972) or even negative (Frazzini and Pedersen, 2014). Consistent with the literature (Bali et al., 2016), we sort stocks into 10 portfolios based on their monthly beta. In particular, we use $M$ months to estimate the market beta on a rolling window using the rollRegres (Christoffersen, 2019) library. We set $M$ to be either 36, 60, or 120 months. For each sample size $M$, we estimate the market beta on a rolling basis. At the end of month $t$, we sort stocks into 10 groups based on their market beta and compute the value-weighted return over the next month at $t+1$. For the next month, we repeat the same procedure until the last month of our data sample.

BETA <- DT[, c("date", "CUSIP", "RET")]

BETA <- merge(BETA, ds[,c("date", "Mkt.RF", "RF")], by = "date")

BETA\$E_RET <- (BETA\$RET - BETA\$RF/100)*100 


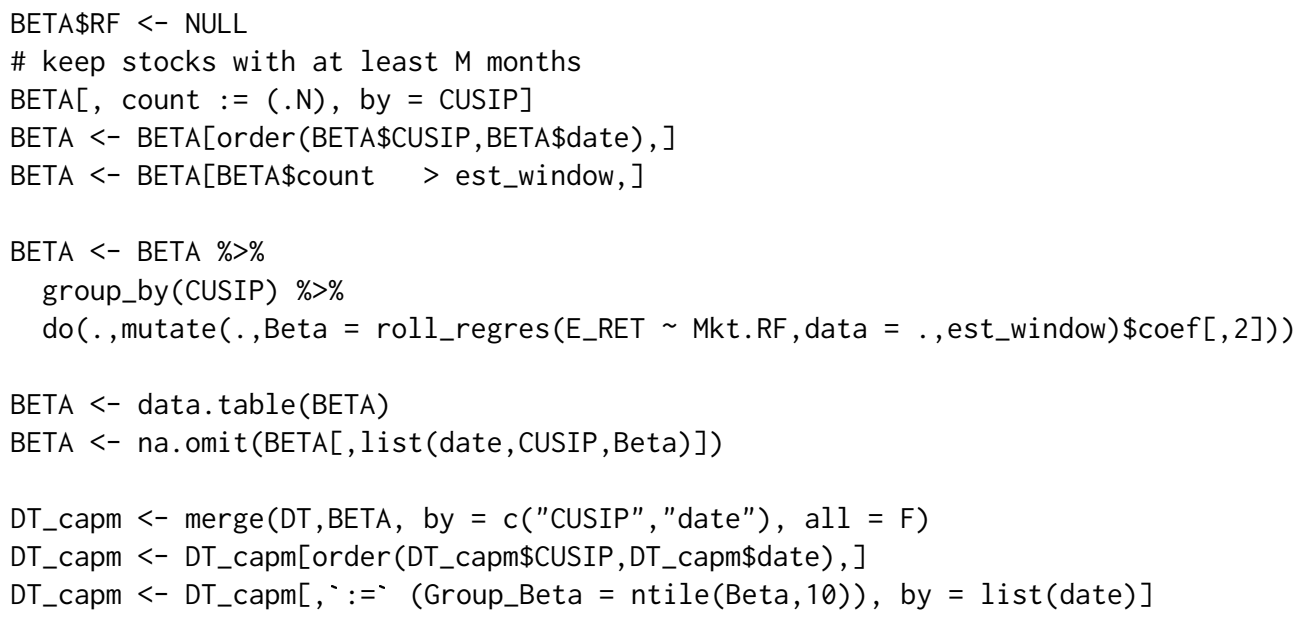

Note that we execute the roll_regres command using the do command in the tidy environment. This approach is the fastest solution to execute a rolling regression for panel data to the best of our knowledge. For instance, when $M=120$, the DT_capm data object contains 1,287,611 observations with 9,149 unique securities. The execution takes about 10 seconds. Given the data object DT_capm, we compute the next month's portfolio value-weighted return as follows:

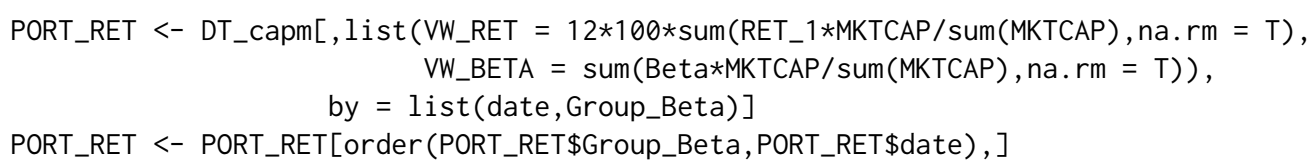

Finally, we summarize the results using ggplot2 in Figure 6. Note that the dashed line denotes the relationship implied by the CAPM. Figure 6 is consistent with Figure 2 from Fama and French (2004), where the slope (intercept) denotes the average annual market excess (risk-free) return. We compute the slope and intercept of the CAPM line based on the sub-sample of the Fama-French data set ds that corresponds to the same dates of the portfolio returns.

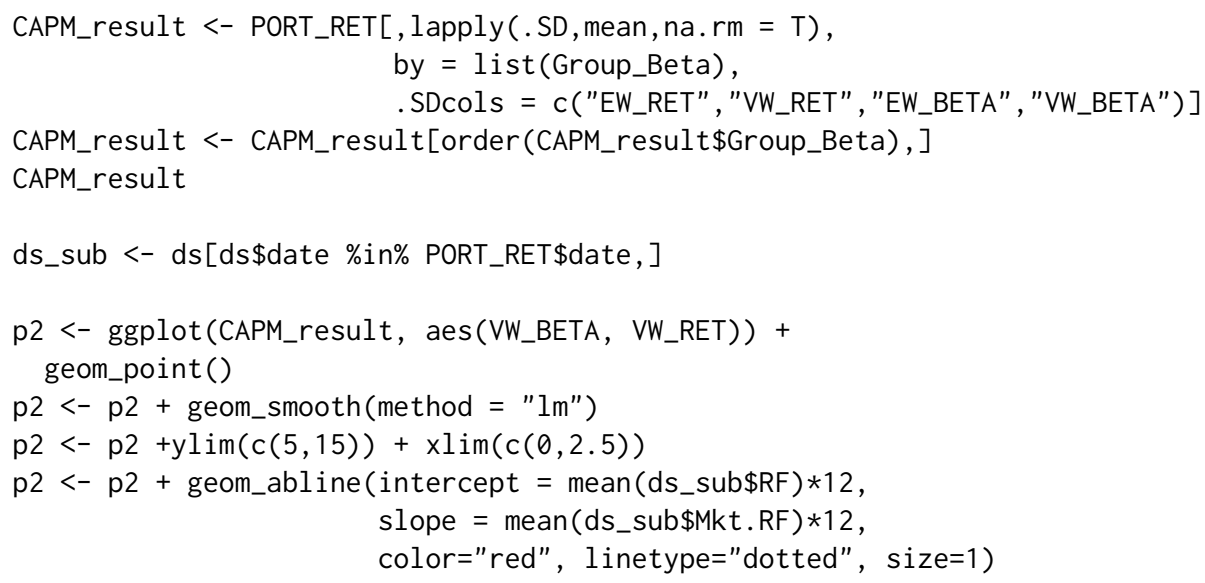

Consistent with Fama and French (2004), we note that the portfolio results denote a flatter line than the one suggested by the CAPM. At the same time, we note that the results are noisy and sensitive to the sample size choice. In unreported results, we find that the negative relationship suggested by Frazzini and Pedersen (2014) is only evident when the betas are estimated using daily returns and portfolios are equally weighted.

\section{Concluding Remarks}

This article provides a brief illustration of merging the CRSP (security prices/returns) data with the COMPUSTAT (financial) data. The illustration is conducted for portfolio formation using book 
Figure 6: Capital Asset Pricing Model

The dots below report the average annualized monthly return ( $y$-axis) versus market beta ( $x$-axis) for the value-weighted portfolios. The solid line is smoothed using linear regression. The dashed line corresponds to the one predicted by the CAPM over the same sample period, where the slope (intercept) denotes the average annual market excess (risk-free) return. Each panel corresponds to a different estimation window needed to estimate the market beta and form beta portfolios on a rolling basis.

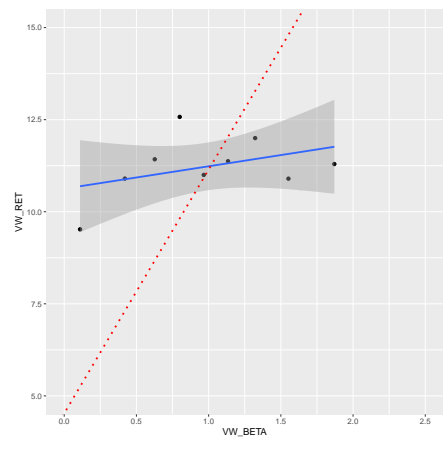

(a) 36 Months Window

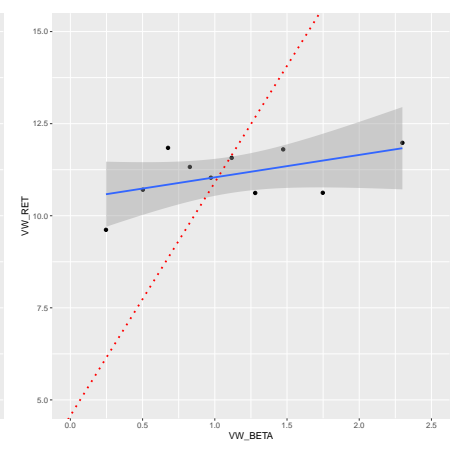

(b) 60 Months Window

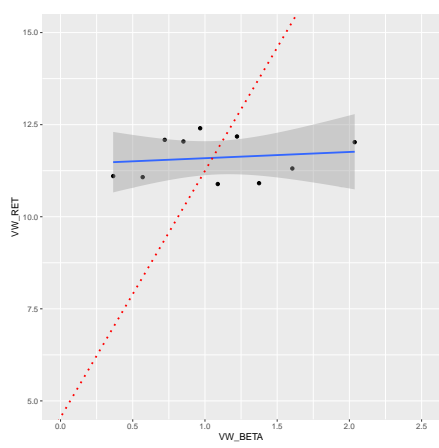

(c) 120 Months Window

data. The final result is combining monthly market data with annual accounting data. However, researchers interested in performing panel analysis or applying predictive models using machine learning may prefer merging the data altogether using the same frequency. We leave this for future research. Nonetheless, we hope this article would encourage further reproducible empirical asset pricing research while also helping bridge the gap between the data science community and the empirical finance literature.

\section{Notes}

An html vignette is found on https://rpubs.com/simaan84/CRSP_COMP. The Rmd source code can be retrieved using the link.

\section{Bibliography}

T. G. Bali, R. F. Engle, and S. Murray. Empirical asset pricing: The cross section of stock returns. John Wiley \& Sons, 2016. [p428, 429, 440]

W. Beaver, M. McNichols, and R. Price. Delisting returns and their effect on accounting-based market anomalies. Journal of Accounting and Economics, 43(2-3):341-368, 2007. [p428]

A. Y. Chen and T. Zimmermann. Open source cross-sectional asset pricing. Available at SSRN, 2020. [p426]

B. Christoffersen. rollRegres: Fast Rolling and Expanding Window Linear Regression, 2019. URL https: //CRAN.R-project.org/package=rollRegres. R package version 0.1.3. [p440]

COMPUSTAT. Compustat north america. URL http://datalib. edina. ac. uk/catalogue/compustat. [p426]

CRSP. Center for research in security prices. URL http://www. crsp.org. [p426]

M. Dowle and A. Srinivasan. data.table: Extension of 'data.frame', 2019. URL https://CRAN. R-project. org/package=data. table. R package version 1.12.8. [p426]

E. F. Fama and K. R. French. Common risk factors in the returns on stocks and bonds. Journal of Finance, 1993. [p426, 430, 431]

E. F. Fama and K. R. French. The capital asset pricing model: Theory and evidence. Journal of economic perspectives, 18(3):25-46, 2004. [p441] 
E. F. Fama and K. R. French. A five-factor asset pricing model. Journal of financial economics, 116(1): 1-22, 2015. [p437]

A. Frazzini and L. H. Pedersen. Betting against beta. Journal of Financial Economics, 111(1):1-25, 2014. [p440, 441]

G. Grolemund and H. Wickham. Dates and times made easy with lubridate. Journal of Statistical Software, 40(3):1-25, 2011. URL http://www. jstatsoft.org/v40/i03/. [p426]

C. R. Harvey, Y. Liu, and H. Zhu. ... and the cross-section of expected returns. The Review of Financial Studies, 29(1):5-68, 2016. [p426]

M. C. Jensen, F. Black, and M. S. Scholes. The capital asset pricing model: Some empirical tests. 1972. [p440]

X. Li, R. N. Sullivan, and L. Garcia-Feijóo. The limits to arbitrage and the low-volatility anomaly. Financial Analysts Journal, 70(1):52-63, 2014. [p426, 440]

J. Lintner. The valuation of risk assets and the selection of risky investments in stock portfolios and capital budgets. Review of Economics and Statistics, 47(1):13-37, 1965. [p440]

R Core Team. R: A Language and Environment for Statistical Computing. R Foundation for Statistical Computing, Vienna, Austria, 2020. URL https: //www.R-project.org/. [p426]

W. F. Sharpe. Capital asset prices: A theory of market equilibrium under conditions of risk. The journal of finance, 19(3):425-442, 1964. [p440]

H. Wickham. The split-apply-combine strategy for data analysis. Journal of Statistical Software, 40(1): 1-29, 2011. URL http://www. jstatsoft.org/v40/i01/. [p426]

H. Wickham. ggplot2: Elegant Graphics for Data Analysis. Springer-Verlag New York, 2016. ISBN 978-3-319-24277-4. URL https://ggplot2. tidyverse.org. [p426]

H. Wickham, R. François, L. Henry, and K. Müller. dplyr: A Grammar of Data Manipulation, 2020. URL https: //CRAN.R-project.org/package=dplyr. R package version 0.8.5. [p426]

Majeed Simaan

School of Business, Stevens Institute of Technology

1 Castle Point Terrace, Babbio Center, Hoboken, NJ 07030, USA.

msimaan@stevens.edu 